\title{
Optimization of Extraction Yield and Phytochemical Characterization of Crude Methanolic Extract and Its Fractions of Mitragyna Speciosa Leaves
}

Nur Haziqah Zakirat Abd Razak

Universiti Putra Malaysia

fazila binti zakaria

Universiti Putra Malaysia

Mohd Basyaruddin bin Abdul Rahman

Universiti Putra Malaysia

Siti Efliza Ashari ( $\boldsymbol{D}$ ctefliza@upm.edu.my )

Department of Chemistry, Faculty of Science, Universiti Putra Malaysia, 43400 UPM, Serdang, Selangor, Malaysia. 2 Integrated Chemical BioPhysics Research, Faculty of Science, Universiti Putra Malaysia, 43400 UPM, Serdang, Selangor, Malaysia. 3 Centre of Foundation Studies for Agricultural Sciences, Universiti Putra Malaysia, 43400 UPM, Serdang, Selangor, Malaysia.

\section{Research article}

Keywords: Mitragyna Speciosa, Response surface methodology, total phenolic content, total flavonoid content, and characterization

Posted Date: August 27th, 2020

DOI: https://doi.org/10.21203/rs.3.rs-52121/v1

License: (c) (1) This work is licensed under a Creative Commons Attribution 4.0 International License. Read Full License 


\section{Abstract}

In this study, Response surface methodology (RSM) was applied to optimize the yield of crude methanolic extract of Mitragyna speciosa leaves using Ultrasound-assisted extraction (UAE). The crude methanolic extract and its fractions were quantified in terms of total phenolic content and total flavonoid content, along with characterized using Fourier-transform infrared and Gas chromatography-mass spectrometry. The results showed the maximum yield of $49.72 \%$ at the optimal conditions (temperature, $34{ }^{\circ} \mathrm{C}$; time, $25 \mathrm{~min}$; and volume of solvent, $166 \mathrm{~mL}$ ). The recovery crude methanolic extract for TPC and TFC were $137.3 \pm 15.7 \mathrm{mg} \mathrm{GAE} / \mathrm{g}$ and $90.3 \pm 15.3 \mathrm{mg} \mathrm{RE} / \mathrm{g}$, respectively.

\section{Introduction}

The development of drugs based on the medical plant has gained new attention due to a great source of therapeutic phytochemicals. Phytochemical compounds such as phenolics and flavonoids are the secondary metabolites that produce abundantly from plant which have been reported to have antioxidant, antibacterial, anticancer, anti-inflammatory properties which is a useful candidate for medical and pharmaceutical industry ${ }^{[1,2]}$. In addition, natural-based formulation products are now become more demanding compared to the synthetic-based product due to its efficiency and safety.

The extraction method is a crucial step in the route of phytochemical production for the discovery of bioactive constituents from plants ${ }^{[3]}$. Lately, a green method such as ultrasound-assisted extraction (UAE), microwave-assisted (MAE), and supercritical fluid extraction (SFE) has been growing rapidly as these methods are fast as compared to conventional like maceration and soxhlet methods. Further, these promising methods are environmental friendly and comparable yield to conventional and even higher ${ }^{[4,5]}$.

Among several green extraction methods, UAE requires reasonable investment in terms of solvent and energy. Moreover, the instrument is simple thus easy to handle, safe, economical and reproducible as it can operate under ambient temperature and at atmospheric pressure ${ }^{[6,7]}$. Phytochemicals from plants can be extracted by acoustic cavitation that produced from ultrasound waves through the solvent and cause damaging the plant's cell walls ${ }^{[8]}$. Besides, mass transfer across cell membranes and penetration of solvent can be improved hence greater extract yields produced ${ }^{[9]}$. Numerous successful studies employed in UAE have been done for the plant samples ${ }^{[10-14]}$. Extraction times, temperatures, temperature, solid to solvent ratios, solvent concentrations, and volume of solvent are the parameters to be optimized to achieve the optimum extraction conditions. These parameters can be optimized by using mathematical and statistical tool viz. response surface methodology (RSM) where it able to considered interaction effects between parameters at one time compared to classical approach and thus shorten the time by reducing the number of experiments needed ${ }^{[15-17]}$.

Liquid-liquid extraction (LLE) or also known as partitioning is one of the techniques used in the subsequence of the extraction process. As the crude plant extract consists of plentiful phytochemical with countless chemical properties, fractionation by different polarities of the solvent can be considered 
because it can improve the quality of chemical characteristics ${ }^{[18]}$. This technique is favorable because it required a simple apparatus and procedure compared with the solid-phase extraction technique.

Mitragyna Speciosa Korth (Rubiaceae family) is a tropical plant that can be found in Southeast Asia countries. M. speciosa is commonly known in Malaysia as 'ketom' or 'biak-biak' and 'kratum' in Thailand. $M$. speciosa has traditionally used as an herbal remedy to relieve tiredness and muscle fatigue, and to treat some common illnesses such as diarrhea, coughing, muscle pain, diabetes, wound, and hypertension. In addition, it is also used as a substitute for opium or morphine in the treatment of drug addicts ${ }^{[19]}$. Numerous studies have revealed several biological activity of $M$. speciosa such as antiinflammation, antinociceptive, antioxidant, antimicrobial ${ }^{[20-23]}$ that are vital in a good healing process.

Due to the great beneficial value of this plant, research is needed to optimize the extraction process to ensure high pharmaceutical quality. To the best of our knowledge, there have been no studies to optimize the extraction yield from the $M$. Speciosa leaves extract. The current study is to optimize the ultrasoundassisted extraction conditions of the $M$. speciosa leaves extract to achieve maximum extraction yield extract by using RSM. Under optimize parameters, the crude methanolic extract was fractionated by liquid-liquid extraction to obtain its fractions. The crude methanolic extract and its fractions were quantified in terms of total phenolic content (TPC) and total flavonoid content (TPC), as well as characterized using Fourier-transform infrared (FTIR) and Gas chromatography-mass spectrometry (GCMS).

\section{Materials And Methods}

\section{Materials}

All the chemicals and reagents used were of analytical grade. Methanol, Folin-Ciocalteu phenol reagents, $\mathrm{AlCl}_{3}$, potassium acetate, gallic acid and rutin were obtained from Sigma-Aldrich (Germany). Sodium carbonate $\left(\mathrm{Na}_{2} \mathrm{CO}_{3}\right)$ was purchased from Merck (Darmstadt, Germany). Distilled water was purified in our laboratory. Fresh leaves of $M$. speciosa were collected from Perak, Malaysia. The plant was identified by botanist and the voucher specimen MFI 0121/19 has been deposited in the herbarium of the Institute of Bioscience, Universiti Putra Malaysia.

\section{Optimization of Extraction Process}

\section{Sample Preparation}

Fresh leaves of $M$. speciosa were thoroughly washed with running tap water. The leaves were cut into small pieces and subjected to freeze-drying method by kept overnight under $-80^{\circ} \mathrm{C}$ after which the frozen leaves were lyophilized. The leaves were milled into a fine powder using a laboratory grinder and the ground leaves were stored in an airtight jar.

\section{Ultrasound-Assisted Extraction}


About $50.0 \mathrm{~g}$ of finely powdered of $M$. speciosa was placed in a conical flask and mixed with methanol. The solution was transferred to an ultrasonic bath (Power Sonic 405, Hwashin Technology Co., Seoul, Korea). The extract was than filtered and concentrated using a rotary evaporator at approximately $40{ }^{\circ} \mathrm{C}$ until the excess solvent was completely removed. Percentage of extraction yields of each run were calculated based on total dry weight according to the Equation (1):

$$
\text { Extraction yield }(\%)=\quad \frac{\text { weight of extract }}{\text { total dry weight }} \times 100
$$

\section{Experimental design}

Response Surface Methodology (RSM) was used to optimize the crude extract from the extraction of $M$. speciosa. Based on Central Composite Design (CCD), 20 experimental runs, with three factors at five levels including six central point were constructed for the optimization process. The CCD was generated by Design Expert Software (Version 11, Stat. Ease Inc., Minneapolis, USA). The influence of independent variables such as the temperature (A), time (B) and volume of solvent (C) on the extraction process were evaluated towards the dependent response (extraction yield). Quadratic model was developed from RSM which describing the extraction process. Table 1 shows the independent variables with the range of its parameters.

Table 1. The independent variables with the range of its parameter.

\begin{tabular}{|llllllll|}
\hline Symbol & Independent variables & Units & \multicolumn{7}{l}{ Coded levels } \\
\cline { 5 - 8 } & & & -1.68 & -1 & 0 & +1 & +1.68 \\
\hline A & Temperature & ${ }^{\circ} \mathrm{C}$ & 30 & 34 & 40 & 46 & 50 \\
\hline B & Time & $\min$ & 15 & 24 & 38 & 51 & 60 \\
\hline C & Volume of solvent & $\mathrm{mL}$ & 50 & 80 & 125 & 170 & 200 \\
\hline
\end{tabular}

\section{Statistical Analysis}

Analysis of variance (ANOVA) is a statistical tool that used to analyze which independent variable is the most significantly affects the percentage yield. All analyses were considered significant at $p<0.05$. Model analysis, lack of fit test, coefficient of determination $\left(R^{2}\right)$, adjusted $R^{2}$ and Predicted vs Actual graph were 
determined for the model adequacy. When $\mathrm{R}^{2}$ values are closer to 1 , the model is considered accurate (Yolmeh et al., 2014). The design was expressed by polynomial regression as shown in Equation (2):

$$
Y=A_{0}+A_{1} X_{1}+A_{2} X_{2}+A_{3} X_{3}+A_{12} X_{1} X_{2}+A_{13} X_{1} X_{3}+A_{23} X_{2} X_{3}+A_{11} X_{1}^{2}+A_{22} X_{2}^{2}+A_{33} X_{3}^{2}
$$

Where $Y$ is the dependant variable (extraction yield); $X_{1}, X_{2}$ and $X_{3}$ are the independent variables (extraction temperature, extraction time and volume of solvent); $A_{0}$ is the regression coefficient at the centre point; $A_{1}, A_{2}$ and $A_{3}$ are linear coefficients; $A_{12}, A_{13}$ and $A_{23}$ are second order coefficients; and $A_{11}$, $A_{22}$ and $A_{33}$ are quadratic coefficients.

\section{Verification of model}

Some random extractions were prepared in order to validate the predicted value. The experimental and predicted value was compared to determine the validity of the model. The percentage of residual standard error (RSE) was calculated for each response. The RSE Equation (3):

$\operatorname{RSE}(\%)=$

(actual value - predicted value)

Predicted value x 100

(3)

\section{Fractionation}

Fractionation was conducted by using liquid-liquid extraction. The optimized conditions obtained from RSM were used to get the crude methanol extract. The crude methanol extract was partitioned between $\mathrm{n}$ hexane and water. The aqueous layer was fractionated by using different polarities based solvents such as $\mathrm{n}$-hexane, dichoromethane, ethyl acetate and butanol successively. Four solvent fractions were collected and concentrated with vacuum rotary evaporator.

\section{Quantification of total phenolic content (TPC) and total flavonoid content (TFC)}

\section{TPC}

By using the Folin-Ciocalteu assay, the total phenolic content of the extracts was determined using method by ${ }^{[24]}$ with several modifications. Each extract of $100 \mu \mathrm{L}$ at a concentration of $1 \mathrm{mg} \mathrm{mL}^{-1}$ or gallic acid standard solution was mixed with $0.5 \mathrm{~mL}$ Folin-Ciocalteu reagent. The mixture was then 
incubated for $3 \mathrm{~min}$ at room temperature and afterwards $1 \mathrm{~mL}$ of $7.5 \%$ sodium carbonate was added. After the mixture was heated for $1 \mathrm{~min}$ at $95^{\circ} \mathrm{C}$ and allowed to cool at room temperature, blue complex formed. Absorbance was measured at $765 \mathrm{~nm}$ using spectrophotometer. The total phenolic compound concentration in extract was expressed in $\mathrm{mg}$ of gallic acid equivalent per gram of dry weight (mg GAE/g) extract.

TFC

Total flavonoid content was ascertained based on the method by Sepulveda et al. ${ }^{[25]}$ with some modification. In brief, $0.5 \mathrm{~mL}$ of sample was mixed with $0.1 \mathrm{~mL}$ of $10 \% \mathrm{AlCl}_{3}, 0.1 \mathrm{~mL}$ potassium acetate and $4.3 \mathrm{~mL}$ of distilled water, followed by $30 \mathrm{~min}$ incubation at room temperature. Absorbance was measured at $415 \mathrm{~nm}$ using a spectrophotometer. The total flavonoid content was expressed as milligram of rutin equivalents (RE) per gram dry matter of extract.

\section{Characterization}

\section{Fourier-Transform Infrared Spectroscopy (FTIR)}

Each extract were mixed with $\mathrm{KBr}$ salt, using mortar and pestle, and compressed into a thin pellet. The absorption spectrum of a chemical compound was determined by infrared spectroscopy. Infrared spectra were recorded on a Perkin-Elmer FTR SPECTRUM BX spectrophotometer between $4000-400 \mathrm{~cm}^{-1}$.

\section{Gas Chromatography- Mass Spectroscopy (GC-MS)}

Crude methanolic extract and its fractions were subjected to GC-MS analysis using the model instrument, GCMS-QP2010 Ultra (Shimadzu Co., Japan) attached with a capillary column DB-1 (0.25 $\mu \mathrm{m}$ film $\times 0.25$ $\mathrm{mm} \mathrm{I.} \mathrm{d.} \times 30 \mathrm{~m}$ length). Analysis was performed by injecting $1 \mu \mathrm{L}$ of the sample with a split ratio of 20 : 1. Helium gas ( $99.9 \%$ ) was used as the carrier gas at a flow rate of $1 \mathrm{~mL} / \mathrm{min}$. The analysis was performed in the El (electron impact) mode with $70 \mathrm{eV}$ of ionization energy. The injector temperature was maintained at $250{ }^{\circ} \mathrm{C}$ (constant). The column oven temperature was set at $50^{\circ} \mathrm{C}$ (held for $3 \mathrm{~min}$ ), raised at $10^{\circ} \mathrm{C}$ per min to $280^{\circ} \mathrm{C}$ (held for $3 \mathrm{~min}$ ), and finally held at $300^{\circ} \mathrm{C}$ for $10 \mathrm{~min}$. The compounds were identified after comparing the spectral configurations obtained with that of available mass spectral database (NIST and WILEY libraries).

\section{Results And Discussion}

\section{Optimization using Response Surface Methodology (RSM)}

RSM was used to optimize the experiment that was designed using Central Composite Design (CCD) via Design Expert 11 Software. RSM was not only optimized, RSM can also investigate the relationship between parameters and its response. There were 20 experiments (three factors five levels) that have been carried out to determine the optimum condition that will produce the highest amount of yield. Table 2 shows the design matrices of the actual and predicted value for extraction of $M$. speciosa. The actual 
value for the response (extraction yield) was from $21.34-50.73 \%$. The predicted values were corresponding to the actual values since achieved from the model fitting technique. Figure 1 illustrates the correlation between predicted and actual values of extraction yield. Most of the points were closed to the line where indicates that the optimum condition for achieving high percentage yield able to determine by the predictability of the model.

The quadratic polynomial model can be expressed by the response after employing multiple regression analysis on the actual. The relationship between the extraction yield, $Y$ with the three independent variables can be described in Equation (4).

$$
Y(\%)=38.62-3.30 A+5.18 B+7.99 C+10.56 A B-0.7575 A C-1.27 B C-0.2568 A^{2}-0.8224 B^{2}-5.03 C^{2}
$$

Where $A$ is extraction temperature $\left({ }^{\circ} \mathrm{C}\right), B$ is extraction time $(\mathrm{min})$, and $\mathrm{C}$ is volume of solvent $(\mathrm{mL})$.

For the statistical analysis, the validity of the model was determined by using analysis of variance (ANOVA) as shown in Table 3. The model that was developed suggested as a quadratic model and significant due to the $F$-value and $p$-value were 146.46 and $<0.0001$ respectively. There is only $0.01 \%$ chance that the $F$-value can lead to the noise. F-value was obtained when an ANOVA test was run and to determine the means between the populations is significantly different, besides $p$-value also can be determined. The $F$-value must be used in combination with $p$-value in order to evaluate the result significantly.

Table 2. The design matrices of the actual and predicted value for extraction of $M$. speciosa 


\begin{tabular}{|c|c|c|c|c|c|}
\hline \multirow{4}{*}{ Run } & \multicolumn{3}{|c|}{ Independent variables } & \multicolumn{2}{|c|}{ Response variable } \\
\hline & A & B & C & & \\
\hline & \multirow[t]{2}{*}{$\begin{array}{l}\text { Temperature } \\
\left({ }^{\circ} \mathrm{C}\right)\end{array}$} & \multirow[t]{2}{*}{$\begin{array}{l}\text { Time } \\
(\min )\end{array}$} & \multirow[t]{2}{*}{$\begin{array}{l}\text { Volume of solvent } \\
(\mathrm{mL})\end{array}$} & \multicolumn{2}{|c|}{$\begin{array}{l}\text { Extraction yield } \\
\text { (\%) }\end{array}$} \\
\hline & & & & Actual & Predicted \\
\hline 1 & 40 & 38 & 50 & 35.57 & 34.75 \\
\hline 2 & 30 & 38 & 125 & 44.11 & 43.45 \\
\hline 3 & 40 & 38 & 125 & 39.06 & 38.62 \\
\hline 4 & 34 & 24 & 170 & 50.66 & 51.21 \\
\hline 5 & 40 & 60 & 125 & 45.24 & 45.01 \\
\hline 6 & 46 & 24 & 170 & 21.34 & 21.97 \\
\hline 7 & 34 & 51 & 80 & 36.45 & 33.51 \\
\hline 8 & 40 & 38 & 125 & 38.56 & 38.62 \\
\hline 9 & 40 & 38 & 200 & 38.73 & 37.84 \\
\hline 10 & 46 & 51 & 170 & 50.73 & 50.92 \\
\hline 11 & 46 & 24 & 80 & 34.26 & 28.05 \\
\hline 12 & 40 & 38 & 125 & 37.97 & 38.62 \\
\hline 13 & 40 & 38 & 125 & 38.97 & 38.62 \\
\hline 14 & 40 & 38 & 125 & 37.90 & 38.62 \\
\hline 15 & 34 & 24 & 80 & 30.75 & 31.19 \\
\hline 16 & 40 & 15 & 125 & 28.24 & 27.58 \\
\hline 17 & 46 & 51 & 80 & 38.92 & 38.99 \\
\hline 18 & 40 & 38 & 125 & 39.12 & 38.62 \\
\hline 19 & 50 & 38 & 125 & 32.57 & 32.34 \\
\hline 20 & 34 & 51 & 170 & 37.29 & 37.92 \\
\hline
\end{tabular}


The value of the coefficient of determination $\left(R^{2}\right)$ and the adjusted coefficient determination (Adj. $R^{2}$ ) were found high, which were 0.9947 and 0.9879 , respectively, indicating a satisfactory correlation between the independent variables and response. The differences between both $\mathrm{R}^{2}$ were only less than 0.2 which revealed the effectiveness of the model. A model that contains a high value of the coefficient of determination which is more than 0.9 represents the model was a good fit with high correlation ${ }^{[26]}$. Adeq precision was used to measure the signal to noise ratio. In this study, adeq precision was found greater than 4 , which was 47.0226 that indicated an adequate signal. Hence, the designed model can be used to plot the design space.

Apart from that, the "lack-of- fit" of the model should also take into count. The lack-of-fit of this model was not significant which verified the accuracy of the model. According to Quanhong \& Caili [27], they reported that the variation can be predicted accurately based on the lack-of-fit of the model where the value of $F$-value lowers than $p$-value.

Table 3. ANOVA for quadratic polynomial model developed for extraction yield of $M$. speciosa 


\begin{tabular}{|c|c|c|c|c|c|}
\hline Source & Sum of Squares & DF & Mean square & F-value & $p$-value \\
\hline Model & 866.84 & 9 & 96.32 & 146.46 & $<0.0001$ \\
\hline A-Temperature & 87.28 & 1 & 87.28 & 132.71 & $<0.0001$ \\
\hline B-Time & 214.83 & 1 & 214.83 & 326.68 & $<0.0001$ \\
\hline C-Volume of solvent & 256.63 & 1 & 256.63 & 390.24 & $<0.0001$ \\
\hline$A B$ & 456.94 & 1 & 456.94 & 694.84 & $<0.0001$ \\
\hline$A C$ & 2.08 & 1 & 2.08 & 3.16 & 0.1186 \\
\hline BC & 5.82 & 1 & 5.82 & 8.85 & 0.0206 \\
\hline$A^{2}$ & 0.8980 & 1 & 0.8980 & 1.37 & 0.2808 \\
\hline$B^{2}$ & 9.21 & 1 & 9.21 & 14.01 & 0.0072 \\
\hline$c^{2}$ & 134.38 & 1 & 134.38 & 204.34 & $<0.0001$ \\
\hline Residual & 4.60 & 7 & 0.6576 & & \\
\hline Lack -of- fit & 3.10 & 2 & 1.55 & 5.13 & 0.0614 \\
\hline Pure Error & 1.51 & 5 & 0.3015 & & \\
\hline Cor Total & 871.45 & 16 & & & \\
\hline $\mathrm{R}^{2}$ & 0.9947 & & & & \\
\hline Adjusted $\mathrm{R}^{2}$ & 0.9879 & & & & \\
\hline Predicted $\mathrm{R}^{2}$ & 0.8870 & & & & \\
\hline Adeq Precision & 47.0226 & & & & \\
\hline
\end{tabular}

\section{Effect of Independent Variables}

\section{Effects of temperature and time}

Based on Figure 2, the volume of the solvent was being fixed at $125 \mathrm{~mL}$ and interaction on the extraction yield of $M$. speciosa. When the extraction temperature of $40{ }^{\circ} \mathrm{C}$ and the extraction time at $15 \mathrm{~min}$, the extraction yield was found to be the lowest yield (28.24\%), Meanwhile when the time at the maximum of 60 min and temperature at $40^{\circ} \mathrm{C}$, the highest extraction yield (45.24\%) was achieved. These indicated that as the extraction time increases with extraction temperature, a higher amount of production able to obtain due to having significant conditions that able to release all the metabolites from the plant. Cares et al. ${ }^{[28]}$ has reported that UAE was able to disrupt the biological membranes which enhance the release of 
compounds from plant and also able to improve mass transfer. Furthermore, thermally unstable compounds can obtain from using UAE ${ }^{[29]}$.

\section{Effects of temperature and volume of solvent}

As shown in Figure 3, the effects of temperature and volume of solvent towards the extraction yield of $M$. speciosa were evaluated. The response surface plot was generated with the fixed extraction time at 38 min and the interaction on response. The highest yield of extraction (44.11\%) was obtained when the temperature was at $30^{\circ} \mathrm{C}$ and used $125 \mathrm{~mL}$ amount of solvent. However, when the higher temperature was applied which was $50^{\circ} \mathrm{C}$ and used the same volume of solvent $(125 \mathrm{~mL})$, the percentage yield was $32.57 \%$. Thus, from these findings, it represented that the compounds in M. speciosa were heat-sensitive; hence will lowering the production yield as temperature increases. Another study by Sheng et al. ${ }^{[30]}$ stated that some thermo-sensitive compounds such as flavonoids will degrade as exposed to high temperatures. Meanwhile, at the temperature of $40^{\circ} \mathrm{C}$ and $200 \mathrm{~mL}$ of solvent used, the yield was $38.73 \%$ which lower compared to a similar condition $\left(40^{\circ} \mathrm{C}\right)$ and has $150 \mathrm{~mL}$ of solvent used.

\section{Effects of time and volume of solvent}

Figure 4 illustrates the effect of time and volume of solvent towards the extraction yield. At the fixed temperature of $40^{\circ} \mathrm{C}$, an increasing volume of solvent will influence the yields where $38.73 \%$ yield was obtained by using $200 \mathrm{~mL}$ of solvent for $38 \mathrm{~min}$ for the extraction process. In contrast, similar conditions, with different volumes of solvent used $(125 \mathrm{~mL})$ results in $39.06 \%$ yield. This can be concluded that the volume of solvent has little effect on extraction yield.

\section{Optimum condition of extraction process of $M$. speciosa}

In order to obtain the optimum condition for the extraction process, the desirability function was evaluated. The highest amount of yields able to achieve from the optimum condition by considering all of the independent variables. From the study, the maximum extraction yield $(49.72 \%)$ was optimized at 34 ${ }^{\circ} \mathrm{C}$ of extraction temperature, in $25 \mathrm{~min}$ and the volume of solvent was $166 \mathrm{~mL}$. The RSE percentage of the optimum condition was below $5 \%$ and represented the model was in good concurrence. The optimum conditions for the extraction yield of $M$. speciosa were tabulated in Table 4. There is no work reported on $\%$ yield crude methanolic extract. However, Orio et al. ${ }^{[31]}$ revealed that \% crude extract in methanol: water, $1: 1$ was $24.8 \%$ where the conditions were at $25^{\circ} \mathrm{C}$ for 1 hour.

Table 4. Optimum conditions for extraction yield

\begin{tabular}{|c|c|c|c|c|c|c|}
\hline \multirow[t]{2}{*}{$\begin{array}{l}\text { temperature } \\
\left({ }^{\circ} \mathrm{C}\right)\end{array}$} & \multirow[t]{2}{*}{$\begin{array}{l}\text { time } \\
(\min )\end{array}$} & \multirow[t]{2}{*}{$\begin{array}{l}\text { Volume of solvent } \\
(\mathrm{mL})\end{array}$} & \multicolumn{3}{|l|}{$\begin{array}{l}\text { yield } \\
\text { (\%) }\end{array}$} & \multirow[t]{2}{*}{ Desirability } \\
\hline & & & Actual & Predicted & RSE & \\
\hline 34 & 25 & 166 & 49.72 & 50.77 & 2.07 & 1.000 \\
\hline
\end{tabular}




\section{Verification of the models}

Three randomized validation sets were carried out to verify the model and to determine the competency of the model. The actual results were compared to the predicted value by measure the residual standard error (RSE) percentage, where the RSE percentage need to below than $5 \%$. To reveal the model was adequate for the extraction process, the RSE percentage must not have significant differences between actual values and predicted values. As shown in Table 5, the model was verified since all of the set experiments contain RSE\% below than 5. The equation of RSE\% was shown in Equation (3).

Table 5. Predicted and actual response value for the verification of model

\begin{tabular}{|llllllll|}
\hline Set & temperature $\left({ }^{\circ} \mathrm{C}\right)$ & time & Volume of solvent & \multicolumn{3}{c|}{ Extraction yield (\%) } \\
\cline { 5 - 7 } & & $(\mathrm{min})$ & $(\mathrm{mL})$ & Actual & Predicted & RSE \\
\hline 1 & 36 & 26 & 160 & 45.24 & 46.20 & 2.08 \\
\hline 2 & 35 & 25 & 166 & 47.11 & 48.73 & 3.32 \\
\hline 3 & 45 & 49 & 140 & 47.80 & 48.68 & 1.81 \\
\hline
\end{tabular}

\section{Quantification of TPC and TFC}

Table 6 shows the TPC and TFC for crude methanolic extract and its fractions of $M$. Speciosa leaves. The phenolic content was found to be more in ethyl acetate fraction. The order of TPC of M. speciosa extracts was: ethyl acetate fraction $(277.7 \pm 10.1 \mathrm{mg} \mathrm{GAE} / \mathrm{g})>$ dichloromethane fraction (184.3 $\pm 18.8 \mathrm{mg} \mathrm{GAE} / \mathrm{g}$ ) $>$ methanol crude $(137.3 \pm 15.7 \mathrm{mg} \mathrm{GAE} / \mathrm{g})>$ hexane fraction $(100.2 \pm 7.8 \mathrm{mg} \mathrm{GAE} / \mathrm{g})>$ butanol fraction (72.4 $\pm 7.3 \mathrm{mg} \mathrm{GAE} / \mathrm{g}$ ). The flavonoid content was found to be more in methanol. The order of TFC was: methanol crude $(90.3 \pm 15.3 \mathrm{mg} \mathrm{RE} / \mathrm{g})>$ ethyl acetate fraction $(75.7 \pm 17.8 \mathrm{mg} \mathrm{RE} / \mathrm{g})>$ dicholoromethane fraction $(54.9 \pm 19.0 \mathrm{mg} \mathrm{RE} / \mathrm{g})>$ butanol fraction $(46.3 \pm 5.7 \mathrm{mg} \mathrm{RE} / \mathrm{g})>$ hexane fraction $(28.1 \pm 10.7 \mathrm{mg}$ $\mathrm{RE} / \mathrm{g})$.

In the present study, the TFC of crude methanolic extract was similar with the previous study done by Parthasarathy et al. ${ }^{[23]}$ which was $90.3 \mathrm{mg} \mathrm{RE} / \mathrm{g}$ and $91.1 \mathrm{mg} \mathrm{RE} / \mathrm{g}$ respectively. However, variation between TPC in the M. speciosa with those reported by previous studies was observed. TPC obtained from crude methanolic extract was more (137.3 mg GAE /g) compared to previous studies reported by Parthasarathy et al. ${ }^{[23]}$ which was $105.58 \mathrm{mg} \mathrm{GAE} / \mathrm{g}$ while a lower TPC (24.02 mg GAE/g) was reported by Lee, S.T. et al. ${ }^{[32]}$. These differences might be due to the usage of modern extraction which was ultrasound-assisted extraction (UAE) and environment conditions where it influences the amount of TPC 
[33]. A study by Zhou et al., ${ }^{[34]}$ on Melastoma sanguineum shows that UAE improved the extraction efficiency and saved a lot of time compared with maceration extraction. Additionally, the present plant was collected from a different location. For most of the plants, change in one of environmental factors such as light, soil water, temperature, soil fertility, and salinity may affect the accumulation of secondary metabolites ${ }^{[35]}$. However there is no investigation has been conducted towards hexane, dichloromethane, ethyl acetate, and butanol extract of $M$. speciosa.

Table 6. TPC and TFC of crude methanolic extract and its fractions of $M$. Speciosa leaves

\begin{tabular}{|lll|}
\hline Extract & $\begin{array}{l}\text { TPC } \\
(\mathrm{mg} \mathrm{GAE} / \mathrm{g})\end{array}$ & $\begin{array}{l}\text { TFC } \\
(\mathrm{mg} \mathrm{RE} / \mathrm{g})\end{array}$ \\
\hline Crude methanolic extract & $137.3 \pm 15.7$ & $90.3 \pm 15.3$ \\
\hline Hexane fraction & $100.2 \pm 7.8$ & $28.1 \pm 10.7$ \\
\hline Dicholoromethane fraction & $184.3 \pm 18.8$ & $54.9 \pm 19.0$ \\
\hline Ethyl Acetate fraction & $277.7 \pm 10.1$ & $75.7 \pm 17.8$ \\
\hline Butanol fraction & $72.4 \pm 7.3$ & $46.3 \pm 5.7$ \\
\hline
\end{tabular}

\section{Characterization of crude methanolic extract and its fractions}

\section{FTIR analysis}

Variation of peaks shows in Figure 5 indicated the various functional groups are obtained in the crude methanolic extract and its fractions of $M$. speciosa leaves.

Figure 5a represents the FTIR spectrum of crude methanolic crude extract. At $3336.85 \mathrm{~cm}^{-1}$, the presence of hydroxyl group was found with strong absorption. N-H stretching was found at the absorption band of $2924.09 \mathrm{~cm}^{-1}$. Furthermore, at the absorption band of $1732.08 \mathrm{~cm}^{-1}, \mathrm{C}=0$ stretching was identified. The aromatic ring was identified at $1695.43 \mathrm{~cm}^{-1}$. At $1367.83 \mathrm{~cm}^{-1}$ of absorption peak, C-N stretching was found, while C-O stretching was presence at $1062.78 \mathrm{~cm}^{-1}$.

Figure $5 \mathrm{~b}$ illustrates the FTIR spectrum of hexane extract. Based on the FTIR spectrum, $\mathrm{O}-\mathrm{H}$ stretching was presence at the absorption peak of $3385.07 \mathrm{~cm}^{-1}$. Next, $\mathrm{N}-\mathrm{H}$ stretching was found at $2924.09 \mathrm{~cm}^{-1}$. $\mathrm{C}=\mathrm{O}$ stretching, $\mathrm{C}=\mathrm{C}$ stretching and $\mathrm{C}-\mathrm{O}$ stretching were presence at the absorption peak of $1735.93 \mathrm{~cm}^{-1}$, $1622.13 \mathrm{~cm}^{-1}$ and $1058.92 \mathrm{~cm}^{-1}$, respectively.

FTIR spectrum of dichloromethane extract was shown in Figure 5c. At the highest absorption peak, $\mathrm{O}-\mathrm{H}$ stretching was found at $3282.84 \mathrm{~cm}^{-1}$, followed by N-H stretching was at the absorption peak of 2931.80 
$\mathrm{cm}^{-1} \cdot \mathrm{C}=\mathrm{O}$ and $\mathrm{C}=\mathrm{C}$ stretching were presence at the region of $1600 \mathrm{~cm}^{-1}$ to $1700 \mathrm{~cm}^{-1}$. Furthermore, $\mathrm{C}-0$ stretching was presence at $1244.09 \mathrm{~cm}^{-1}$. Lastly, C-N stretching was found at the absorption peak of $1103.28 \mathrm{~cm}^{-1}$.

Figure $5 \mathrm{~d}$ represents FTIR spectrum of ethyl acetate extract. At $3223.05 \mathrm{~cm}^{-1}, \mathrm{O}-\mathrm{H}$ stretching was detected at the absorption peak. $\mathrm{N}-\mathrm{H}$ stretching was found at $2941.44 \mathrm{~cm}^{-1}, \mathrm{C}=0$ stretching was found at 1681.93 $\mathrm{cm}^{-1}$ and N-O stretching was found at $1516.05 \mathrm{~cm}^{-1}$. Besides, N-O stretching and $\mathrm{C}-\mathrm{N}$ stretching were presence at the absorption peak of $1516.05 \mathrm{~cm}^{-1}$ and $1278.81 \mathrm{~cm}^{-1}$, respectively.

FTIR spectrum of $n$-butanol crude extract of was shown in Figure $5 \mathrm{e}$. Based on the figure, the highest absorption was at $3317.56 \mathrm{~cm}^{-1}$ due to the presence of $\mathrm{N}-\mathrm{H}$ stretching. Besides, $\mathrm{C}=\mathrm{C}$ stretching was exist at $1602.85 \mathrm{~cm}^{-1}$. In addition, $\mathrm{O}-\mathrm{H}$ bending was presence at $1406.11 \mathrm{~cm}^{-1}$, followed by $\mathrm{C}-\mathrm{N}$ stretching that can be found at $1047.35 \mathrm{~cm}^{-1}$.

The FTIR analysis crude methanolic extract and its fractions of $M$. speciosa leaves showed the presence of multiple functional groups such as alcohols, carboxylic acids, alkenes, amides, esters which may represent different phytochemical classes which not limited to phenols and flavonoids only. Thus, the compounds can be verified through the result of GC-MS.

\section{GC-MS analysis}

The crude methanolic extract and its fractions of $M$. Speciosa leaves were further characterized using GCMS. A total of 64 phytocompounds were found in the crude methanolic extract and its fraction contained more than $1 \%$ area (Table 7). These compounds belong to different chemical classes, including alcohol, esters of fatty acids, steroids/triterpenes, aldehydes, ketones, and amides, Among the crude fractions, hexane fraction have more phytocompounds same with crude methanolic extracts such as $3,7,11,15-$ tetramethyl-2-hexadecen-1-ol, hexadecanoic acid, phytol, 9,12,15-octadecatrienoic acid, squalene, campesterol, and stigmasterol. Ethyl acetate and dichloromethane fractions have no phytocompound same with the crude methanolic extract.

The presence of various bioactive compounds detected by GC-MS such as stigmasterol, campesterol, phytol, squalene, hexadecanoic acid, benzenesulfonamide, and hydroquinone justifies the used of the $M$. speciosa for various skin ailments treatment. In addition, stigmasterol is one the types of sterol found in the most plant has been studied for its pharmacological potential, including cytotoxic, antimutagenic, antioxidant, antitumoral, among other herbal approaches to pathological states in principles and practice of phytotherapies ${ }^{[36]}$.

Table 7. Main phytocompounds found in the crude methanolic extract and its fractions of M.speciosa leaves by GC-MS. 


\begin{tabular}{|c|c|c|c|}
\hline Extract & Compounds & $\begin{array}{l}\text { Retention time } \\
\text { (min) }\end{array}$ & $\begin{array}{l}\text { Area } \\
(\%)\end{array}$ \\
\hline \multirow{18}{*}{$\begin{array}{l}\text { Crude methanol } \\
\text { extract }\end{array}$} & Glycerin & 4.053 & 2.73 \\
\hline & Ethanol & 6.821 & 1.40 \\
\hline & 2-cyclohexen-1-one & 6.963 & 1.35 \\
\hline & 1,2,3,5-cyclohexanetetrol & 11.748 & 13.30 \\
\hline & beta-D- Mannofuranoside & 12.182 & 5.72 \\
\hline & 3,7,11,15-Tetramethyl-2-hexadecen-1-ol & 12.645 & 1.11 \\
\hline & Hexadecanoic acid & 12.891 & 2.32 \\
\hline & Scyllo-Inositol & 13.384 & 1.55 \\
\hline & 9,12-Octadecadienoic acid & 16.324 & 1.19 \\
\hline & $9,12,15$-Octadecatrienoic acid & 13.769 & 2.06 \\
\hline & Phytol & 13.815 & 1.04 \\
\hline & 2-hydroxy-1-(hydroxymethyl)ethyl ester & 15.600 & 2.68 \\
\hline & Squalene & 16.765 & 5.17 \\
\hline & 5-beta-Cholest-24-en-12-one & 17.735 & 1.60 \\
\hline & 2H-1-Benzopyran-6-ol & 18.662 & 1.01 \\
\hline & Campesterol & 19.660 & 1.79 \\
\hline & Stigmasterol & 19.878 & 1.13 \\
\hline & Gamma-Sitosterol & 20.484 & 3.36 \\
\hline \multirow{10}{*}{$\begin{array}{l}\text { Hexane } \\
\text { fraction }\end{array}$} & 1-Dodecanol & 10.447 & 55.70 \\
\hline & 3,7,11,15-Tetramethyl-2-hexadecen-1-ol & 12.433 & 4.26 \\
\hline & n-Hexadecanoic acid & 13.177 & 1.77 \\
\hline & Phytol & 13.822 & 1.73 \\
\hline & $9,12,15$-Octadecatrienoic acid & 14.052 & 1.72 \\
\hline & Squalene & 16.770 & 1.14 \\
\hline & $\mathrm{E}, \mathrm{Z}-1,3,12$-Nonadecatriene & 18.659 & 1.03 \\
\hline & Methyl (Z)-5,11,14,17-eicosatetraenoate & 18.744 & 1.64 \\
\hline & Campesterol & 19.700 & 1.35 \\
\hline & Stigmasterol & 19.906 & 1.03 \\
\hline
\end{tabular}




\begin{tabular}{|c|c|c|c|}
\hline & Beta-Sitosterol & 20.561 & 3.68 \\
\hline \multirow{17}{*}{$\begin{array}{l}\text { Dichloromethane } \\
\text { fraction }\end{array}$} & 2-methyl-2-pentanol & 3.567 & 1.31 \\
\hline & 3-methyl-3-pentanol & 3.808 & 3.09 \\
\hline & 1-Hydroxy-1-methylcyclopentane & 4.306 & 14.69 \\
\hline & 3-Methylcyclopentanol & 4.927 & 1.91 \\
\hline & 7-0xabicyclo[4.1.0]heptane & 12.322 & 1.66 \\
\hline & 2-Phenylquinoline-4-carboxylic acid & 15.845 & 1.10 \\
\hline & $\begin{array}{l}\text { 1-(Diethylamino)-3-methylpyrido[1,2- } \\
\text { a]benzimidazole-4-carbonitrile }\end{array}$ & 16.760 & 1.49 \\
\hline & 3-Methyl-3H-cyclonona[def]biphenylene & 17.742 & 1.72 \\
\hline & Cholest-24-en-12-one & 17.764 & 5.07 \\
\hline & Speciofoline & 18.726 & 4.05 \\
\hline & Dibenzo[a,h]cyclotetradecene & 18.850 & 2.08 \\
\hline & $\begin{array}{l}\text { Spiro[3H-indole-3,4'-[4H- } \\
1,6] \text { methanoquinoline]-4'a(5'H)-carboxylic acid }\end{array}$ & 19.029 & 5.94 \\
\hline & Mitragynine & 21.421 & 12.95 \\
\hline & Silane & 21.680 & 6.31 \\
\hline & Corynan-16-carboxylic acid & 21.933 & 4.00 \\
\hline & Benzoic acid & 21.942 & 1.23 \\
\hline & Urs-12-en-28-oic acid & 24.617 & 1.80 \\
\hline \multirow{10}{*}{$\begin{array}{l}\text { Ethyl Acetate } \\
\text { fraction }\end{array}$} & Phenol & 6.711 & 1.76 \\
\hline & 2-0xabicyclo[3.2.0]hepta-3,6-diene & 6.969 & 1.33 \\
\hline & 2,5-Dimethyl-2,3-dihydro-5H-1,4-dioxepine & 7.186 & 1.81 \\
\hline & O-Methoxyphenol & 7.558 & 1.19 \\
\hline & Silane & 8.550 & 1.71 \\
\hline & 1,2-Benzenediol & 8.566 & 9.07 \\
\hline & Benzofuran & 8.681 & 5.78 \\
\hline & 1,4:3,6-Dianhydro-alpha-d-glucopyranose & 8.721 & 2.55 \\
\hline & Phosphonic acid & 8.828 & 8.78 \\
\hline & 2-Methoxy-4-vinylphenol & 9.332 & 1.60 \\
\hline
\end{tabular}




\begin{tabular}{|llll|} 
& D-Allose & 10.882 & 6.84 \\
\hline 3',5'-Dimethoxyacetophenone & 10.983 & 2.26 \\
\hline N-Decanoic acid & 11.811 & 16.38 \\
\hline 2(3H)-Naphthalenone & 11.994 & 1.89 \\
\hline Beta-D-Mannofuranoside & 12.179 & 4.60 \\
\hline Benzenesulfonamide & 12.351 & 1.34 \\
\hline \multirow{3}{*}{ Butanol } & Oxirane & 12.417 & 2.23 \\
\hline Furfural & 4H-Pyran-4-one & 4.850 & 1.11 \\
\hline 2-Furancarboxaldehyde & 8.230 & 1.37 \\
\hline Hydroquinone & 9.086 & 8.03 \\
\hline 1,2,3,5-Cyclohexanetetrol & 9.425 & 2.06 \\
\hline 6-Ethoxy-6-methyl-2-cyclohexenone & 12.841 & 28.99 \\
\hline 4-O-Methylmannose & 13.497 & 9.22 \\
\hline Inositol & 14.238 & 28.15 \\
\hline
\end{tabular}

\section{Conclusions}

In this study, the optimization of the crude methanolic extract from the extraction process of $M$. speciosa leaves was successfully achieved by using RSM utilizing UAE method. The optimized conditions were: temperature $\left(34^{\circ} \mathrm{C}\right)$, time $(25 \mathrm{~min})$ and volume of solvent $(166 \mathrm{~mL})$ with optimized percentage yield obtained was $49.72 \%$. The extraction yield of crude extract was similar to the RSM's predicted value. The RSE percentage for validation sets were all below $5 \%$, which indicated the model was verified. Under these conditions, the recovery of crude methanolic extract for TPC and TFC were $137.3 \pm 15.7 \mathrm{mg} \mathrm{GAE} / \mathrm{g}$ and $90.3 \pm 15.3 \mathrm{mg} \mathrm{RE} / \mathrm{g}$, respectively. However, ethyl acetate fraction showed the highest $(277.7 \pm 10.1 \mathrm{mg}$ $\mathrm{GAE} / \mathrm{g})$ and TFC $(75.7 \pm 17.8 \mathrm{mg} \mathrm{RE} / \mathrm{g})$ compared to other fractions. Based on the present study, $M$. speciosa leaves extract could potentially be used in the development of drug formulation for targeted therapeutic as it contained higher phenolic and flavonoid content as well as other valuable phytocompounds.

\section{Declarations}

Ethics approval and consent to participate: Not applicable Consent for publication: Not applicable 
Availability of data and materials: available

Competing interests: No potential conflict of interest was reported by any of the authors.

Funding: None

Author Contributions: Conceptualization and Methodology: N.H.Z.A.R., F.Z., M.B.A.R and S.E.A. Resources: F.Z., S.E.A and M.B.A.R. Investigation, Formal Analyses, and Writing Original Draft: N.H.Z.A.R. and F.Z. Supervision and Review of the final Draft: S.E.A.

\section{Acknowledgements: None}

\section{References}

(1) Huang, Y., Xiao, D., Burton-Freeman, B. M., \& Edirisinghe, I. (2016). Chemical Changes of Bioactive Phytochemicals during Thermal Processing. Reference Module in Food Science. Elsevier. https://doi.org/10.1016/b978-0-08-100596-5.03055-9

(2) Tyug, T. S., Johar, M. H., \& Ismail, A. (2010). Antioxidant properties of fresh, powder, and fiber products of mango (Mangifera foetida) fruit. International Journal of Food Properties, 13(4), 682-691. https://doi.org/10.1080/10942910902741834

(3) Abarca-Vargas, R., Peña Malacara, C. F., \& Petricevich, V. L. (2016). Characterization of chemical compounds with antioxidant and cytotoxic activities in bougainvillea $\mathrm{x}$ buttiana holttum and standl, (Var. rose) extracts. Antioxidants, 5(4). https://doi.org/10.3390/antiox5040045

(4) Xu, D. P., Li, Y., Meng, X., Zhou, T., Zhou, Y., Zheng, J., ... Li, H. Bin. (2017). Natural antioxidants in foods and medicinal plants: Extraction, assessment and resources. International Journal of Molecular Sciences, 18(1), 20-31. https://doi.org/10.3390/ijms18010096

(5) Dhanani, T., Shah, S., Gajbhiye, N. A., \& Kumar, S. (2017). Effect of extraction methods on yield, phytochemical constituents and antioxidant activity of Withania somnifera. Arabian Journal of Chemistry, 10, S1193-S1199. https://doi.org/10.1016/j.arabjc.2013.02.015

(6) Medina-Torres, N., Ayora-Talavera, T., Espinosa-Andrews, H., Sánchez-Contreras, A., \& Pacheco, N. (2017). Ultrasound assisted extraction for the recovery of phenolic compounds from vegetable sources. Agronomy, 7(3). https://doi.org/10.3390/agronomy 7030047

(7) Kaltsa, O., Lakka, A., Grigorakis, S., Karageorgou, I., Batra, G., Bozinou, E., ... Makris, D. P. (2020). A green extraction process for polyphenols from elderberry (Sambucus nigra) flowers using deep eutectic solvent and ultrasound-assisted pretreatment. Molecules, 25(4), 1-17. https://doi.org/10.3390/molecules25040921

(8) Vı, R., \& Zamora-gasga, M. (2018). Optimization of ultrasonic-assisted extraction of phenolic compounds from Justicia spicigera leaves, 27, 1093-1102. https://doi.org/10.1007/s10068-018-0350-0 
(9) Altemimi, A., Watson, D. G., Choudhary, R., \& Dasari, M. R. (2016). Ultrasound Assisted Extraction of Phenolic Compounds from Peaches and Pumpkins, 1-20. https://doi.org/10.1371/journal.pone.0148758

(10) Wang, B., Qu, J., Luo, S., Feng, S., Li, T., Yuan, M., ... Ding, C. (2018). Optimization of ultrasoundassisted extraction of flavonoids from olive (olea europaea) leaves, and evaluation of their antioxidant and anticancer activities. Molecules, 23(10). https://doi.org/10.3390/molecules23102513

(11) Majeed, M., Hussain, A. I., Chatha, S. A. S., Khosa, M. K. K., Kamal, G. M., Kamal, M. A., Liu, M. (2016). Optimization protocol for the extraction of antioxidant components from Origanum vulgare leaves using response surface methodology. Saudi Journal of Biological Sciences, 23(3), 389-396.

https://doi.org/10.1016/j.sjbs.2015.04.010

(12) Kim, S., \& Mabrouki, F. (2017). Comptes Rendus Chimie Optimization of ultrasound-assisted extraction of bioactive alkaloids from Stephania cambodica using response surface methodology Optimisation de I' extraction assist ee par ultrasons des alcaloïdes bioactifs de Stephania cambodica , 20, 996-1005. https://doi.org/10.1016/j.crci.2017.09.004

(13) Shirzad, H., Niknam, V., Taheri, M., \& Ebrahimzadeh, H. (2017). Ultrasound-assisted extraction process of phenolic antioxidants from Olive leaves: a nutraceutical study using RSM and LC - ESI - DAD - MS. Journal of Food Science and Technology, 54(8), 2361-2371. https://doi.org/10.1007/s13197-0172676-7

(14) Zhong, L., Liu, Y., Xiong, B., Chen, L., Zhang, Y., \& Li, C. (2019). Optimization of Ultrasound-Assisted Extraction of Total Flavonoids from Dendranthema indicum var . aromaticum by Response Surface Methodology, 2019.

(15) Silva, E. M., Rogez, H., \& Larondelle, Y. (2007). Optimization of extraction of phenolics from Inga edulis leaves using response surface methodology. Separation and Purification Technology, 55(3), 381387. https://doi.org/10.1016/j.seppur.2007.01.008

(16) Zainol, S., Basri, M., Basri, H. Bin, Shamsuddin, A. F., Abdul-Gani, S. S., Karjiban, R. A., \& Abdul-Malek, E. (2012). Formulation optimization of a palm-based nanoemulsion system containing levodopa. International Journal of Molecular Sciences, 13(10), 13049-13064.

https://doi.org/10.3390/ijms131013049

(17) Melgar, B., Dias, M. I., Barros, L., Ferreira, I. C. F. R., Rodriguez-Lopez, A. D., \& Garcia-Castello, E. M. (2019). Ultrasound and microwave assisted extraction of Opuntia fruit peels biocompounds:

Optimization and comparison using RSM-CCD. Molecules, 24(19), 1-16.

https://doi.org/10.3390/molecules24193618

(18) Suhaimi, S. H., Hasham, R., Khairul, M., \& Idris, H. (n.d.). Optimization of Ultrasound-Assisted Extraction Fractionation from Orthosiphon stamineus Benth. 
(19) Srichana, K., Janchawee, B., Prutipanlai, S., Raungrut, P., \& Keawpradub, N. (2015). Effects of mitragynine and a crude alkaloid extract derived from Mitragyna speciosa korth. On permethrin elimination in rats. Pharmaceutics, 7(2), 10-26. https://doi.org/10.3390/pharmaceutics7020010

(20) Shaik Mossadeq, W. M., Sulaiman, M. R., Tengku Mohamad, T. A., Chiong, H. S., Zakaria, Z. A., Jabit, M. L., ... Israf, D. A. (2009). Anti-inflammatory and antinociceptive effects of Mitragyna speciosa Korth methanolic extract. Medical Principles and Practice, 18(5), 378-384. https://doi.org/10.1159/000226292

(21) Azizi, J., Ismail, S., Mordi, M. N., Ramanathan, S., Said, M. I. M., \& Mansor, S. M. (2010). In vitro and in vivo effects of three different mitragyna speciosa korth leaf extracts on phase II drug metabolizing enzymes-glutathione transferases (GSTs). Molecules, 15(1), 432-441.

https://doi.org/10.3390/molecules15010432

(22) Goh, T. B., Yian, K. R., Mordi, M. N., \& Mansor, S. M. (2014). Antioxidant value and antiproliferative efficacy of mitragynine and a silane reduced analogue. Asian Pacific Journal of Cancer Prevention, 15(14), 5659-5665. https://doi.org/10.7314/APJCP.2014.15.14.5659

(23) Parthasarathy, S., Azizi, J. Bin, Ramanathan, S., Ismail, S., Sasidharan, S., Mohd, M. I., \& Mansor, S. M. (2009). Evaluation of antioxidant and antibacterial activities of aqueous, methanolic and alkaloid extracts from Mitragyna speciosa (rubiaceae family) leaves. Molecules, 14(10), 3964-3974. https://doi.org/10.3390/molecules 14103964

(24) Soraya, I., Sulaiman, C., Basri, M., Chan, K. W., Ashari, S. E., Reza, H., ... Ismail, M. (2015). African Journal of Pharmacy and Pharmacology In vitro antioxidant, cytotoxic and phytochemical studies of Clinacanthus nutans Lindau leaf extracts, 9(34), 861-874. https://doi.org/10.5897/AJPP2015

(25) Sepulveda-, G., Reyna-Aqui, C., Chaires-Ma, L., Bermudez-T, K., \& Rodriguez-, M. (2009). Antioxidant Activity and Content of Phenolic Compounds and Flavonoids from Justicia spicigera. Journal of Biological Sciences, 9(6), 629-632. doi: 10.3923/jbs.2009.629.632

(26) Jumbri K, Al-Hanif Rozy MF, Ashari SE et al. (2015). Optimisation and characterisation of lipase catalysed synthesis of a kojic monooleate ester in a solvent-free system by response surface methodology. PLoS ONE 10:e014466448.

(27) Quanhong, L., \& Caili, F. (2005). Application of response surface methodology for extraction optimization of germinant pumpkin seeds protein. Food Chemistry, 92(4), 701-706.

(28) Cares MG, Vargas Y, Gaete L, Sainz J, Alarcon J. (2009). Ultrasonically assisted extraction of bioactive principles from Quillaja Saponaria Molina. Physics. Procedia. 3: 169-178.

(29) Wu, Jianyong \& Lin, LD \& Chau, Foo Tim. (2001). Ultrasound-assisted extraction of ginseng saponins from ginseng roots and cultured ginseng cells. Ultrasonics sonochemistry. 8. 347-52. 10.1016/S13504177(01)00066-9. 
(30) Sheng, Z.L., Wan, P.F., Dong, C.L. and Li, Y.H. (2013). Optimisation of total flavonoids content extracted from Flos Populi using response surface methodology. Industrial Crops and Products 43: 778786.

(31) Orio, L., Alexandru, L., Cravotto, G., Mantegna, S., \& Barge, A. (2012). Ultrasonics Sonochemistry UAE, MAE , SFE-CO 2 and classical methods for the extraction of Mitragyna speciosa leaves. Ultrasonics Sonochemistry, 19(3), 591-595. https://doi.org/10.1016/j.ultsonch.2011.10.001

(32) Lee, S. Y., Mediani, A., Nur Ashikin, A. H., Azliana, A. B. S., \& Abas, F. (2014). Antioxidant and aglucosidase inhibitory activities of the leaf and stem of selected traditional medicinal plants.International Food Research Journal, 21(1), 165-172.

(33) Ghafoor K, Choi YH, Jeon JY, Jo IH. (2009). Optimization of ultrasound-assisted extraction of phenolic compounds, antioxidants, and anthocyanins from grape (Vitis Vinifera) seeds. Agric. Food Chem. 57: 4988-4994. doi :10.1021/jf9001439.

(34) Zhou, T., Xu, D. P., Lin, S. J., Li, Y., Zheng, J., Zhou, Y., ... Chatel, G. (2017). Ultrasound-assisted extraction and identification of natural antioxidants from the fruit of Melastoma sanguineum Sims. Molecules, 22(2), 1-15. https://doi.org/10.3390/molecules22020306

(35) Yang, L., Wen, K. S., Ruan, X., Zhao, Y. X., Wei, F., \& Wang, Q. (2018). Response of plant secondary metabolites to environmental factors. Molecules, 23(4), 1-26.

https://doi.org/10.3390/molecules23040762

(36) Gollo, A. L., Tanobe, V. O. A., de Melo Pereira, G. V., Marin, O., Bonatto, S. J. R., Silva, S., ... Soccol, C. R. (2020). Phytochemical analysis and biological activities of in vitro cultured Nidularium procerum, a bromeliad vulnerable to extinction. Scientific Reports, 10(1), 1-13. https://doi.org/10.1038/s41598-02064026-z

\section{Figures}




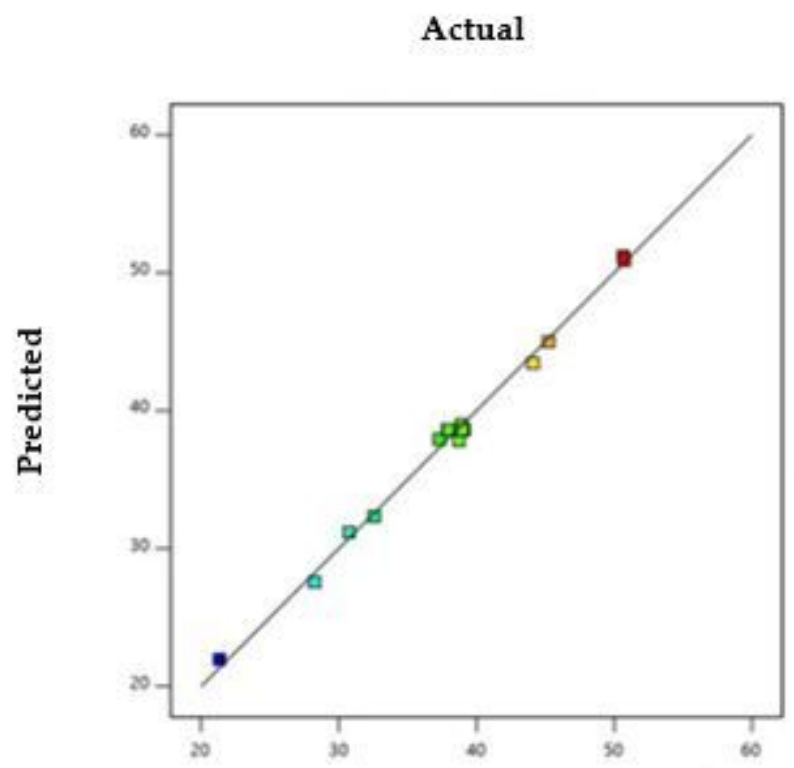

Figure 1

Correlation of predicted and actual values of extraction yield

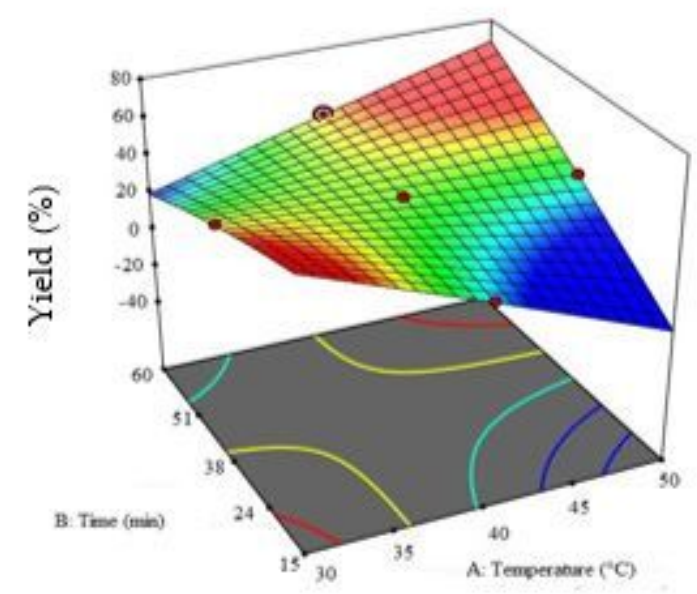

Figure 2

Three-dimensional plot as a function of time, temperature, and interaction on the extraction yield of M. speciosa. 


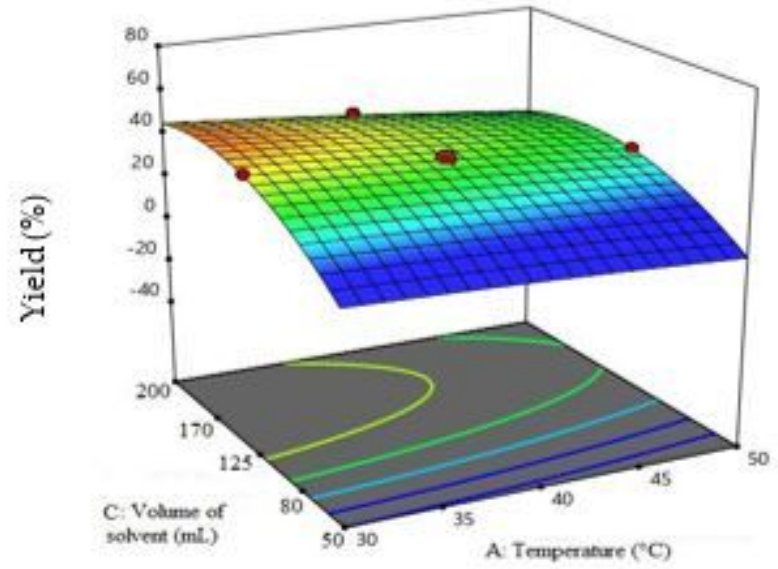

Figure 3

Three-dimensional plot as a function of temperature and volume of solvent and interaction on the extraction yield of M. speciosa.

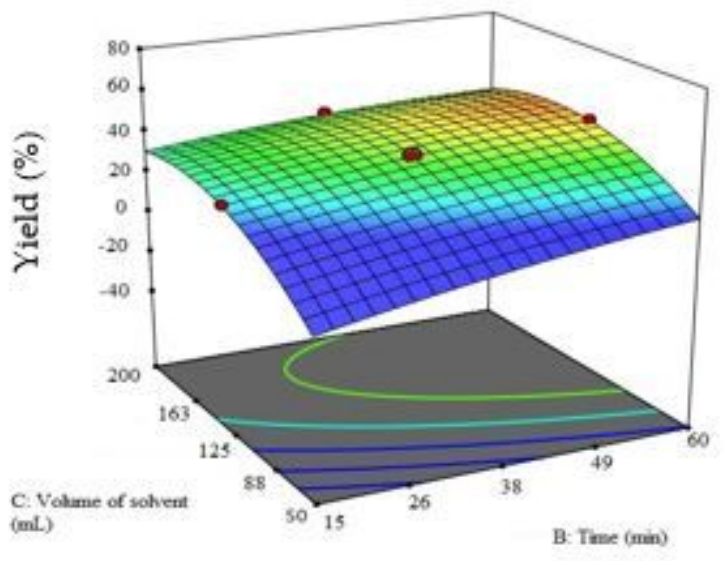

Figure 4

Three-dimensional plot as a function of time, volume of solvent, and interaction on the extraction yield of M. speciosa. 


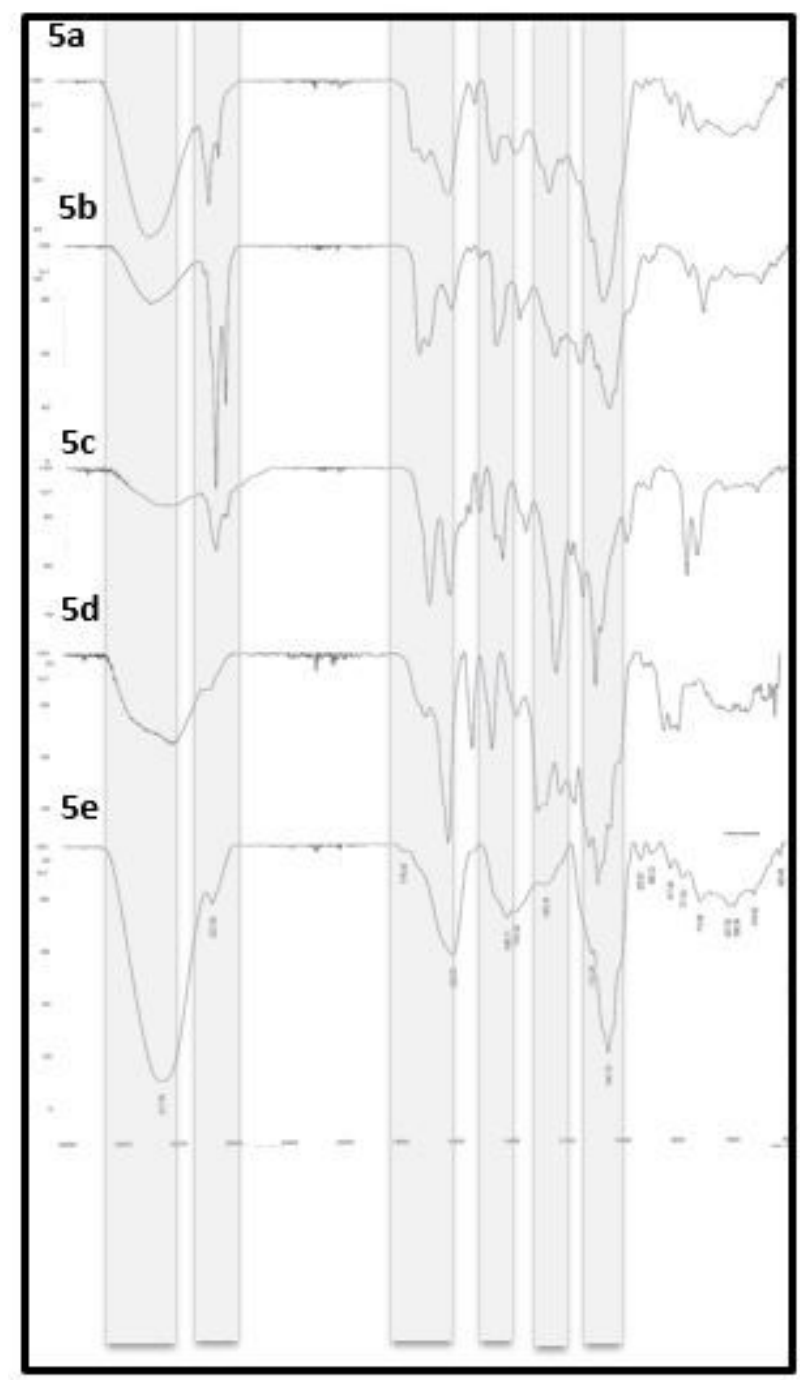

Figure 5

FTIR Spectum of M. speciosa crude methanolic extract and its fractions. 5a) crude methanolic extract. 5b) hexane fraction. 5c) dichloromethane fraction. 5d) ethyl acetate fraction. 5e) butanol fraction. 